\title{
THE DETERMINANTS OF E-GOVERNMENT RELATIONAL MODELS CONSTRUCTION: INTERACTION, COMMUNICATION, PARTICIPATION AND COLLABORATION
}

\author{
Florentina Neamțu ${ }^{1}$ \\ Transylvania University of Brasov \\ florentinavioletaneamtu@gmail.com \\ Bogdan Nichifor \\ Vasile Alecsandri University of Bacău \\ bnichifor@gmail.com
}

\begin{abstract}
In recent decades the integrating approach of new information and communication technologies in the public sector grew faster. Worldwide, most states have made and still make substantiate efforts towards the coherent strategies implementation in order to favor the complex process of integrating the new information and communication technologies. Regardless of the objectives - maximizing efficiency, increase transparency in the decision process, improve service quality or citizen participation in decision making - what we call today e-Government has become an essential mechanism in administrative reforms, independent of aggregation level. The article presents an analysis of the factors that define the outline of the e-government relational model.
\end{abstract}

\section{Keywords}

relational models; e-government; interaction; communication; participation; collaboration

\section{JEL Classification}

M39

\section{Introduction}

If at the conceptual level the e-government platforms necessity is universally accepted, problems and malfunctions occur during the implementation and effective use; this reality is common, both externally, being associated to the differences between states of the world in terms of development of e-government platforms, and internally, as evidenced by the gap between the sophistication level of online services provided by the central and local public entities.

Despite this difference, the common starting point in the relationship model construction and in the e-government platforms development is considered to be the opportunities offered by new information and communication technologies from the perspective of expanding the interaction, participation and collaboration in public entities area

\section{Theories on the evolution of e-government platforms}

In the context of the society changes which are associated to the accelerate progress in the XXI century, the opportunity to improve bi-directional information flow and the

\footnotetext{
${ }^{1} \mathrm{PhD}$ student at Interdisciplinary Doctoral School in Marketing, "Transilvania” University of Braşov
} 
reconfiguration of framework for collaboration between the public and the various stakeholders categories are real challenges. The high interest for these issues is evidenced by numerous academics searches on identifying methodologies and models that explain the new information exchange coordinates and the locally, nationally and internationally data integration architecture (Dawes, 2010; Gant, 2003; Gelder, Maesschalck and Colsoul 2010; Klievink and Janssen, 2010; Navarrete, Gil-Garcia, Mellouli, Pardo and Scholl, 2010; Papenfuss and Schaefer, 2010; Williamset et al., 2009; Zheng, Yang, Pardo and Jiang, 2009) .

In fact, since 1996, Dawes foreshadow the benefits and the challenges associated with information sharing initiatives, considering that "government portals will become a central technical component for interaction, participation and collaboration activities within networks consisting of governmental and nongovernmental actors".

The e-government issue in terms of Internet portals functions utility in the public system has been also the subject of numerous investigations.

One of the first research steps that have provided an initial perspective on the use of new information and communication technologies in the public sector services was conducted in 2001 in the United States. The study offered by Kaylor, Deshazo and VanEck (2001) is based on a comprehensive research approach to e-government platforms, in which the sample was composed of 123 municipalities whose population vary between 100,000 to 200,000 inhabitants. Looking at the e-government platforms development degree and the online services sophistication level, the three authors have shown that "there is a direct link between the city size and the phenomena of egovernment platforms adoption".

This link has also been identified in 2002 by Moon, according to which "the city size and the governance type are key factors on the e-government platforms implementation and development". The author points out that unlike central government entities in which they observed a proactive attitude in e-government platforms uptake, the local entities are clearly far from the potential results and foreshadowed expectations in the use of new information and communication technologies.

Later, in 2004, based on a U.S. cities research, Reddick suggests a two-stage model that explains the phenomenon of increasing local e-governance. If the first stage suggests the use of data catalog, the second shows a higher level of sophistication, namely the creation of transactional framework. Referring to the two dimensions, the author revealed that "in the G2C relations area, the public services are focused on cataloging categories, while in the G2G and G2B partnerships, which are more advanced, that has been reached the transactional level."

Similar studies were conducted by Al-Nuaimi (2009), Attour - Oueslati, Dufresne and Longhi (2007), Baker, Hanson and Myhill (2009), Hahamis, Iles and Healy (2005), Williams (2008) etc.

A special dimension of this research was the studying of various websites of egovernment in terms of functions that facilitate the closeness to the various stakeholders categories.

Such an analysis was provided by Gant and Gant (2002), showing that "web portals serve as an integrated gateway into local government websites, offering a single point of contact for the provision of online services at the local government level".

Later, in 2008, Sandoval - Almazan and Gil -Garcia revealed that, by mixing existing applications in e-government portals, has been created the field for "moving from oneway information and data exchange to a more interactive involvement with people". In fact, as has been shown in the theory and practice, the recent technological 
innovations are those that have supported this development, examples being Web 2.0 and related instruments.

\section{Interaction, communication, participation and collaboration: construction pylons for relational models in public system practice}

In the last decade the e-government portals have recorded a constant evolution, this dynamic being in fact a response to the new Internet features. We are witnesses to the "radical transformations of portals functions and the principles and interaction framework with citizens and other social actors" (Lips, 2010). Currently, as revealed by Sandoval-Almazan and Gil-Garcia (2010), government websites can be considered such as "communication systems through a computer and the Internet".

In the literature and practice area there are listed a multitude of models explaining the government websites development and evolution (Gil -Garcia and Martinez- Moyano, 2007; Layne and Lee, 2001; Sandoval - Almazan and Gil -Garcia, 2008, 2010). One of the most commonly used approaches is the evolutionary perspective that creates stages and analyzes e-government initiatives upon the characteristics and technical aspects found in every development stage. This approach has proved its usefulness in the government websites principles decoding process, offering both effective levers to quantify the innovation degree and recommendations and directions to follow in improving framework approach. In fact, as has been specified by the advocates of this theory, it appears that each of these steps is already an electronic governance form.

Although the 5 stages of e-government platforms development approach (information, interaction, transaction, integration and participation) have been proposed as complementary components, and not necessarily mutually exclusive, they can be easily presented as determinants in the construction of relational models.

\subsection{The availability of information}

A core function of e-government portals is that of the public information display (Kun Chang, Melih, Sangjae and GyooGun, 2008; Susan, 2004). Government disclosure format is extremely important, at least in light of the website attractiveness. In the world practice are found numerous presentations: some portals are using traditional structures such as folders or menus, others allow users to search for information using a search engine, and more recently, some of them use multimedia tools (video, audio applications or online presentations). Despite the differences in public information structure, all these forms are trying to create the optimum framework to become closer to citizens.

Regarding the effectiveness of different ways of structuring public information, the practice of developed countries provides numerous studies. For example, a research conducted by Buccoliero and Bellio in 2010 which aimed to identify web content strategy in Italian town of Venice, revealed that: "the release of the information should be directly related to back-office structures of the local government". This idea is supported also by Gould, Gomez and Camacho (2010) who stating that "the provision of timely and accurate information is related to internal efficiency and organizational structure”.

\subsection{Quality public services}

The opportunity of improving public services quality through e-government platforms is widely accepted. In the context of the present analysis the interest is granted to the quality as a determinant factor of the relation models construction. 
Each of the relational models components can be a target for public services and there is a clear evidence of segmentation approaches (G2G, G2B, G2C etc.). However, there are differences between these services categories, both in terms of sophistication level and the integration degree of online conventional benefits. This can affect the relationship with the various stakeholders categories given the trend of "change, of stakeholder expectations regarding online services".

Considered to be fundamental in the relational models construction and implementation, this approach that may improve the quality of online public services has been the subject of numerous reform processes (Connolly, Bannister and Kearney, 2010; Papenfuss and Schaefer, 2010 etc.). Moreover, in the literature and practice areas there are provided some alternatives to government web portals, namely the use of mobile phones as information and communication support.

\subsection{Increasing interaction frequency}

The world practice has revealed that many government portals, both central and local, currently use Web 2.0 tools and applications. However, as academic researchers mentioned there are very few the portals that show a clear operational and assimilation of interaction strategy (Sandoval - Almazan, Diaz- Murillo, Gil -Garcia, Luna- Reyes 2010).

The interaction in terms of e-government platforms must be analyzed in two dimensions, as follows:

- an internal dimension (G2G and G2E) which facilitate intra-organizational interaction among central and local public entity and between civil servants and operational staff of central/local government etc. This interaction can be both a restricted or a private one which is developed on the Intranet mechanisms applications and an extended or concentrated one, which is group specialized (blogs, social media). In fact, many Web 2.0 applications such as blogs and social media (Twitter and Facebook) can be used both as a support to promote domestic participation in a structured way and as leverage for creating and development of internal relations, favoring the decision making convergence (Ballejos and Montagna 2010). According to a study provided by Noveck, in 2009, other interaction tools beyond e-mail and Intranet can be "the wiki collaboration, the mental mapping or using RSS and forums".

- an external dimension that fosters both interaction with citizens (G2C) and with different legal entities (G2B, G2N). According to the studies conducted by Noveck (2009) and Tapscott and Williams (2010), the e-government portals that are using wiki applications are real tools for sharing ideas and solutions and to promote the public dialogue. Other channels of interaction with civil society or legal entities are: the blog, through which can be promoted initiatives, can be disseminated new ideas or can be developed dialogue with different groups of stakeholders; the new Web 2.0 applications such as social networks: Twitter and Facebook, through which can be disseminated, with a broad coverage, news, messages, warnings or ideas of governance; social tags; RSS (syndication content); podcasts etc. Obviously, the interaction with the different stakeholders categories can occur also in the absence of Web 2.0 applications, such as comments in the specific area in the e-government portals that both aim to encourage the public expression of opinions and the extensive use of chat sessions on specific subjects with various officials. 


\subsection{Multiplication of participation channels}

Civil society, in general, has provided many channels for participation in government. According to academics, these channels may vary from those of the framework facilitating participation in the democratic process (Anthopoulos, SiO, Tsoukalas, 2007), to the one specific to transaction area (Boyer-Wright, Kottemann, 2008).

Need for a multi-channel strategy, as a mechanism to enhance the participation of citizens in government, has been the subject of numerous studies in the academic area. In 2008, Ebbers, Pieterson and Noordman proposed such a strategy to expand opportunities of citizens towards exchange of information and knowledge. This idea is supported by:

- Gil-Garcia, Chun and Janssen (2009), according to whom "participation has the ability to create value for citizens and government organizations";

- Barnes and Vidgen (2007), who states that "the e-government sites are a gateway to electronic channels of participation";

- Ong and Wang (2009), who consider that the interaction with officials and government agencies, and the stakeholder participation, expanded after use of "online surveys, forum sites , blogs ...”.

In the literature there are studies that show the impact of the lack of interaction on the level of participation of stakeholders in the actions of public entities . Such studies are provided by Fink (2010) and Resca (2010), according to whom the low level of interaction and related approaches inconsistency may affect the involvement of stakeholders in participatory approach.

The most used channels participation in government portals are the polls and forums. These unidirectional tools facilitate the engagement of citizens in relation to government, allowing the expression of opinions 24 hours from 24, 7 days out of 7 , be it attitude on policies and policy statements, or opinions regarding any malfunction of public services.

Despite the clear benefits generated (involvement and participation of citizens in government action), these channels are associated with a major disadvantage, namely the lack of direct and rapid feedback from the Government. This phenomenon occurs because many government officials were not aware of these forums and polls (Matheus, Ribeiro, 2009) .

Although it offers great benefits, e- mail is another tool that can facilitate engagement and customization bond between citizens and civil servants.

\subsection{Creating new opportunities for collaboration}

Collaboration is the last component, and perhaps most important, of the approach of building a relational model of e-government. Usually, people access government portals to obtain information and data, both as inputs to their decision making and as a simple cognitive actions to ensure consistency. Moreover, global practice has shown that very little of them want explicitly to work with different entities of the public system.

Importance of collaboration in e-government platforms comes, as revealed by numerous academic studies (Inglehart, 1997; Parent, Vandebeek and Gemino, 2005; Tolbert and Mossberger, 2006 etc.) from the direct relationship between it and the level of confidence of civil society in government action.

According to various surveys, citizens, regardless of geographical location, show consistently low levels of trust in government. Against this background, it was observed that the use of applications such as wikis and social networks (Facebook, Twitter), given their ability to accelerate the phenomenon of interaction and thus 
multiplying forms of collaboration, generated an improvement of level of public confidence indicator.

In the context of the proposed analysis should be noted that public confidence indicator covers not only the relational dimension specific to G2C, but also includes working with various non-profit organizations (G2N) and even the media (newspapers, television, radio) which, in democratic context, are essential components.

Based on the reduced frequency of collaboration between different stakeholders and the government, in the literature there are works that indicate that "this type of partnership is characteristic, predominantly, in emergencies, context in which the government portal is perceived as an alternative channel for access to public information that support decision-making” (Maldonado, Maitland, Tapia, 2010).

Obviously this theory is constantly criticized in academia, most studies noting that the new role of citizens, in an interconnected global environment, is to be a "prosumer: producer and consumer of information at the same time" regardless of the existence of a crisis situations or not.

For other academics, research on collaboration and sharing of information revealed the need for reconfiguration of government processes, organizational structures and procedures.

In this context, a new organizational paradigm was proposed, namely Public Sector Knowledge Networks, considering that the exchange of information and their sharing through the networks improve government processes and facilitate collaboration . To support the previous statement, Dawes , Cresswell and Pardo (2009) explains the difference between the new paradigm and the classical public network: "as opposed to other types of networks, Public Sector Knowledge Networks (PSKN) deals with information and knowledge sharing beyond traditional boundaries of the organization, trying to meet public needs that one organization canot manage in an independent manner". This type of network requires the existence of bidirectional relationships between people, processes, software and other information technology. Like interaction, collaborative approach can be analyzed in two dimensions: an external dimension that reveals the collaboration between government and stakeholders, and an internal dimension, which emphasizes partnerships between different levels of the public system.

Collaboration with various categories of stakeholders can involve many instruments. For example, e-government portals may have the warning systems (Dawes, Prefontaine, 2003), designed to identify any failures or security threats, the context in which stakeholders would use it to alert the authorities.

Similarly, there are many forms of collaboration within internal relations of the public system. One option is the collaboration between different entities or between local and central level to provide a common framework for the provision of online services.

\section{Conclusions}

Regardless of the nature and type of relationship, e-government portal is a hub of opportunities for collaboration and exchange of information between government and non-governmental actors. 


\section{References}

Al-Nuaim, H. A. (2009), How "E" are Arab municipalities? An evaluation of Arab capital municipal web sites, International Journal of Electronic Government Research, 5(1), 50-63.

Anthopoulos, L. G., Siozos, P., Tsoukalas, I. A. (2007), Applying participatory design and collaboration in digital public services for discovering and re-designing egovernment services, Government Information Quarterly, 24(2), 353-376.

Attour-Oueslati, A., Dufresne, D., Longhi, C. (2007), The development of the local Eadministration: Empirical evidences from the French case, Paper presented at The 6th International Conference, EGOV, 2007, available on http://www. springerlink.com.

Baker, P. M. A., Hanson, J., Myhill, W. N. (2009), The promise of municipal WiFi and failed policies of inclusion: The disability divide, Information Polity, 14(1-2), 47-59.

Ballejos, L. C., Montagna, J. M. (2010), Identifying interorganisational network; a factor-based approach, International Journal of Networking and Virtual Organisation, 7(1), 1-22.

Barnes, S. J., Vidgen, R. (2007), Interactive E-government: Evaluating the web site of the UK inland revenue, International Journal of Electronic Government Research, 3(1).

Boyer-Wright, K. M., Kottemann, J.E. (2008), High-level factors affecting global availability of online government services, System Sciences (HICSS), 41rd Hawaii International Conference on, Kauai, 7-10 January, available on http://ieeexplore.ieee.org/xpl/articleDetails.

Buccoliero, L., Bellio, E. (2010), Citizens web empowerment in European municipalities, Journal of E-Governance, 33(4), 225-236.

Dawes, S.S. (2010). Information policy meta-principles: Stewardship and usefulness, System Sciences (HICSS), 1-10, 43rd Hawaii International Conference on, Kauai, 5-8 January, available on http://ieeexplore.ieee.org/xpl/ articleDetails.

Dawes, S.S. (1996), Interagency information sharing: Expected benefits, manageable risks, Journal of Policy Analysis and Management, 15(2), 377-394.

Dawes, S.S., Cresswell, A.M., Pardo, T.A. (2009), From "need to know" to "need to share": Tangled problems, information boundaries and the building of public sector knowledge networks, Public Administration Review, 69(3), 392-402.

Dawes, S.S., Prefontaine, L. (2003), Understanding new models of collaboration for delivering government services, Association for Computing Machinery, Communications of the ACM, 46(1).

Ebbers, W.E., Pieterson, W.J., Noordman, H.N. (2008), Electronic government: Rethinking channel management strategies, Government Information Quarterly, 25(2), 181-201.

Gant, J.P. (2003), Delivering e-government services through the Access Indiana Information Network, Albany, New York, Center for Technology in Government.

Gant, J.P., Gant, D.B. (2002), Web portal functionality and state government eservice, System Sciences, HICSS, Proceedings of the 35th Annual Hawaii International Conference, available on http://ieeexplore.ieee.org/

Gelders, D., Brans, M., Maesschalck, J., Colsoul, N. (2010), Systematic evaluation of public participation projects: Analytical framework and application based on two Belgian neighborhood watch projects, Government Information Quarterly, 27(2), 134-140. 
Gil-Garcia, J. R., Chun, S. A., Janssen, M. (2009), Government information sharing and integration: Combining the social and the technical, Information Polity, 14(1-2), 1-10.

Gould, E., Gomez, R., Camacho, K. (2010), Information Needs in Developing Countries: How Are They Being Served by Public Access Venues?, Proceedings of the $16^{\text {th }}$ Americas Conference on Information Systems, Lima, Peru, august 12-15, 1-12, available on http://faculty.washington.edu.

Hahamis, P., Iles, J., Healy, M. (2005), e-Government in Greece: Bridging the gap between need and reality, Electronic Journal of e-Government, 3(4), 185-192.

Inglehart, R. (1997), Postmaterialist values and the erosion of institutional authority, in J.S. Nye, P.D. Zelikow, D.C. King (Eds.), Why people don't trust government, 217-237, Harvard College

Kaylor, C., Deshazo, R., Van Eck, D. (2001), Gauging e-government: A report on implementing services among American cities, Government Information Quarterly, 18(4), 293-307.

Klievink, B., Janssen, M. (2010), Simulation games for collaborative development in e-Government, System Sciences (HICSS), 43rd Hawaii International Conference on, Kauai, 5-8 January, retrieved from: http://ieeexplore.ieee.org.

Lips, M. (2010), Rethinking citizen: Government relationships in the age of digital identity: Insights from research, Information Polity, 15(4), 273-289.

Maldonado, E. A., Maitland, C. F., Tapia, A. H. (2010), Collaborative systems development in disaster relief: The impact of multi-level governance, Information Systems Frontiers, 12(1), 9-27.

Matheus, R., Ribeiro, M.M. (2009), Models for citizen engagement in Latin American: Case studies of public digital budgeting, Proceedings of the 3rd International Conference on Theory and practice of electronic governance, available on http://portal.acm.org.millenium.itesm.mx

Moon, M.J. (2002), The evolution of e-government among municipalities: Rhetoric or reality?, Public Administration Review, 62(4), 424-433.

Navarrete, C., Gil-Garcia, J.R., Mellouli, S., Pardo, T.A., Scholl, J. (2010), Multinational e-government collaboration, information sharing, and interoperability: An integrative model, System Sciences (HICSS), 43rd Hawaii International Conference on, Kauai, 5-8 January, available on http://ieeexplore.ieee.org.

Noveck, B.S. (2009), Wiki government: how technology can make government better, democracy stronger, and citizens more powerful, Brookings Institution Press.

Ntaliani, M., Costopoulou, C., Manouselis, N., Karetsos, S. (2009), M-government services for rural SMEs, International Journal of Electronic Security and Digital Forensic, 2(4), 407-423.

Ong, C.S., Wang, S.-W. (2009), Managing citizen initiated email contacts, Government Information Quarterly, 26(3), 498-504.

Papenfuß, U., Schaefer, C. (2010), Improving public accountability by aligning reporting to organizational changes in public service provision - An empirical Internet study of all Austrian, German and Swiss towns and states from an agency-theory perspective, International Review of Administrative Sciences, 76(3).

Parent, M., Vandebeek, C.A., Gemino, A.C. (2005), Building citizen trust through egovernment, Government Information Quarterly, 22(4), 720-736.

Reddick, C.G. (2004), A two-stage model of e-government growth: Theories and empirical evidence for U.S. cities, Government Information Quarterly, 21(1), 51-64. 
Resca, A. (2010), A question of progress: Face-to-face relationships versus face to screen relationships, Paper presented at the MCIS 2010, available on http://www.cersi.it

Sandoval-Almazan, R., Diaz-Murillo, G., Gil-Garcia, J.R., Luna-Reyes, L.F. (2010), Web 2.0 en los portales estatales en México: una primera aproximación, Revista de Administración Pública, XLV(121), 72-81.

Sandoval-Almazan, R., Gil-Garcia, J.R. (2010), Assessing local e-government: An initial exploration of the case of Mexico, Proceeding International Conference on Theory and Practice of Electronic Governance, 61-65, available on http://dl.acm.org.

Sandoval-Almazan, R., Gil-Garcia, J.R. (2010), Limitations of evolutionary approaches to e-government, in G.D. Garson, M. Khosrow-Pour (Eds.), Handbook of research on public information technology, IGI Global, Hershey, PA.

Tapscott, D., Wiliams, A. (2010), Macrowikinomics: Portfolio, Hardcover.

Tolbert, C.J., Mossberger, K. (2006), The effects of e-government on trust and confidence in government, Public Administration Review, 66(3), 354-369.

Williams, C.B., Dias, M., Fedorowicz, J., Jacobson, D., Vilvovsky, S., Sawyer, S., et al. (2009), The formation of inter-organizational information sharing networks in public safety: Cartographic insights on rational choice and institutional explanations, Information Polity, 14(1-2), 13-29.

Williams, M.D. (2008), E-government adoption in Europe at regional level, Transforming Government: People, Process and Policy, 2(1), 47-59.

Zheng, L., Yang, T.M., Pardo, T., Jiang, Y. (2009), Understanding the "boundary” in information sharing and integration, System Sciences (HICSS), 42rd Hawaii International Conference on, Kauai, 5-8 January, available on http://ieeexplore. ieee.org. 